\title{
Selection of acute stroke patients for treatment of visual neglect
}

\author{
S P Stone, P Patel, R J Greenwood
}

\begin{abstract}
Although visual neglect is a predictor of poor outcome after stroke, some patients regain independence, whilst others take up considerable rehabilitation resources. Intensive treatment of visual neglect is available and a knowledge of the predictive features in the recovery of these patients would be helpful in the early selection of patients for treatment. A study was therefore carried out to determine the prognosis of patients presenting with visual neglect at two to three days after stroke. Linear logistic regression showed that the initial degree of paralysis (measured by the Motricity Index), the severity of neglect (measured by the Visual Neglect Recovery Index) and the patient's age were the significant predictors of independence (Barthel score 20), mild dependence (Barthel 15-19), and moderate/severe dependence (Barthel 0-14) in surviving patients at three months and at six months. Regression equations correctly predicted $78 \%$ of outcomes, and had a sensitivity and specificity for "independence" of $84 \%$ and $90 \%$ respectively, and a sensitivity and specificity for "moderate/severe dependence" of $89 \%$ and $80 \%$. It is suggested that these equations may be useful in selecting comparable groups of patients for randomised controlled trials of treatment of visual neglect.
\end{abstract}

(F Neurol Neurosurg Psychiatry 1993;56:463-466)

Patients with visual neglect due to a stroke ignore relevant visual stimuli on the side opposite their cerebral lesion, when carrying out a task or activity. ${ }^{2}$ This may adversely affect many self-care activities and the presence of visual neglect is known to be a predictor of poor outcome in both acute ${ }^{3}$ and convalescent ${ }^{4}$ stroke patients. Such patients take up considerable rehabilitation resources, although some make a good recovery.

Intensive treatment of visual neglect is available. Trials of treatment are divided on its value ${ }^{56}$ but did not match patients in treatment groups according to time after stroke, severity of neglect or prognosis for independence. A knowledge of the predictors of recovery of patients with visual neglect would be helpful in selecting comparable groups of patients for randomised trials of treatment.

Fullerton $e t a l^{3}$ carried out a study which showed that the initial severity of visual neglect was predictive of outcome. Equations were produced estimating the probability of independence. These could be used to allocate patients to trials of treatment. Their study, however, may have omitted a significant proportion of patients with visual neglect by only using one test of neglect. ${ }^{78}$ It may have exaggerated the association of visual neglect with a poor outcome by giving the mean neglect score to patients too ill to be assessed for visual neglect, who constituted a third of their population and of whom over $80 \%$ died. Moreover, the categorisation of outcome as recovered, independent, dependent and dead may have diminished the usefulness of the study as the cost of stroke relates mainly to the loss of independence in self-care, rather than to mortality (which occurs early and predictors of which are well known). ${ }^{9}$ Grouping all dependent patients together ignores the implications that the degree of dependency has for service provision. The assessment of self-care used in the study was unstandardised and appeared to exclude washing and dressing. A prognostic study that enabled early identification of the more dependent survivors might be more useful, and thus encourage the development of new therapies to improve outcome.

We therefore carried out such a study. Only the outcome in survivors was considered and "dependent" patients were divided into three groups "mild", "moderate" and "severe", according to their self-care ability as assessed by a standardised measure, the Barthel Index, ${ }^{10}$ that notes the presence of disability and estimates its severity, using a checklist of ten items (transfers, walking, continence of faeces and of urine, feeding, washing, dressing, toiletting, bathing and climbing stairs). A standard battery of 7 tests, a modified form of the Behavioural Inattention Test $^{811}$ was used to increase the detection of patients with visual neglect and the mean neglect score was not given to the patients who were too ill to be assessed for visual neglect.

\section{Method \\ Patients}

A total of 171 consecutive patients mean (SD) age $72.37(12 \cdot 11)$ years, with an acute hemispheric first stroke (69 right hemisphere, 102 left), defined by modified WHO criteria ${ }^{8}$ and admitted to St Bartholomews and Homerton hospitals, were assessed by a clini- 
cian (SPS) two to three days after stroke (table 1). All patients were admitted as emergencies. Patients with subarachnoid haemorrhage were excluded from the study. Patten's criteria were used to define a hemispheric stroke. ${ }^{12} \mathrm{~A}$ total of 156 patients had infarcts and 15 had haemorrhages as assessed by CT brain scan at three to five days (127 patients) or the Guys's diagnostic index ${ }^{13}$ (44 patients). Thirteen patients $(8 \%)$ had lacunar strokes; 11 of the pure motor hemiparesis variety and two of the sensorimotor type. ${ }^{14}$ Of those who were scanned $48(38 \%)$ had no visible lesion, 37 (29\%) had cortical lesions, 20 (16\%) had deep lesions and $22(17 \%)$ had both. The 30 day case fatality rate was $27 \%$.

Ninety eight patients ( 50 right hemisphere, 48 left) had visual neglect detected by a standard battery, ${ }^{8} 37$ had no visual neglect and 36 were too drowsy or aphasic to be assessed for neglect. All patients were followed up at three and at six months to determine outcome, with the following exceptions (table 2): of the patients with visual neglect, five had preexisting disability that affected their independence in self-care, 11 died of non-stroke related disease, five had second strokes and two refused follow up. Of the patients without neglect, two had pre-existing disability, two died of other disease, one had a second stroke and eight were lost to or refused follow up. There were thus 75 patients with neglect, 24 without neglect whose three month outcome was known.

At three months, 10 of the neglect patients died of their stroke or of the consequences of stroke related immobility. None of those without neglect died. There were thus 65 neglect patients and 24 non-neglect patients alive at three months whose outcome was known.

A further two patients were lost to six month follow up, one died of other disease, one extended their stroke and one died of the consequences of stroke-related immobility.

Of the 36 unassessable patients, 27 were dead at three months, and the rest were severely dependent.

\section{Outcomes}

Outcome at three months and at six months was assessed by Wade $e t$ al s modification ${ }^{15}$ of the Barthel Index which measures independence in self-care, using the checklist of ten

Table 1 Patient characteristics

\begin{tabular}{|c|c|c|c|c|c|c|}
\hline \multicolumn{2}{|c|}{ Hemisphere } & \multirow[b]{2}{*}{ Infarct } & \multirow[b]{2}{*}{ Haemorrhage } & \multirow{2}{*}{$\begin{array}{l}\text { Visual } \\
\text { neglect }\end{array}$} & \multirow{2}{*}{$\begin{array}{l}\text { No visual } \\
\text { neglect }\end{array}$} & \multirow{2}{*}{$\begin{array}{l}\text { Unable to be } \\
\text { assessed }\end{array}$} \\
\hline Right & Left & & & & & \\
\hline 69 & 102 & 156 & 15 & 98 & 37 & 36 \\
\hline
\end{tabular}

Table 2 Factors excluding patients from three month follow up.

\begin{tabular}{lllll}
\hline & $\begin{array}{l}\text { Previous } \\
\text { disability }\end{array}$ & $\begin{array}{l}\text { Death unrelated } \\
\text { to stroke }\end{array}$ & $\begin{array}{l}\text { Subsequent } \\
\text { stroke }\end{array}$ & $\begin{array}{l}\text { Refused } \\
\text { follow up }\end{array}$ \\
\hline Visual neglect & 5 & 11 & 5 & 2 \\
No neglect & 2 & 2 & 1 & 8 \\
\hline
\end{tabular}

activities of daily living described above. To each of these is allotted a score. The individual scores are summated to give the Barthel score, out of a maximum of 20 . Outcome was then categorised in the standard manner ${ }^{10}$ as "Independent" (Barthel score 20), "Mild Dependence" (Barthel 15-19), "Moderate Dependence" (Barthel 10-14), "Severe Dependence" (Barthel 0-9).

\section{Clinical assessments}

Visual neglect was assesed by a modified version of the Behavioural Inattention Test, ${ }^{11}$ which had been standardised for patients with acute stroke. ${ }^{8}$ Its severity was measured by the Visual Neglect Recovery Index (VNRI). ${ }^{16}$ This expresses performance on six tests from the battery (Pointing to Objects, Meal, Reading a menu, Line cancellation, Star Cancellation and Coin selection) as a percentage of complete recovery from the maximum measurable visual neglect. A score of $0 \%$ indicates maximal visual neglect and a score of $100 \%$ indicates no visual neglect. Strategies for assessing patients with aphasia have been described elsewhere. ${ }^{8}$

The following features of the neglect syndrome and related disorders were also assessed using standardised definitions and methods ${ }^{17}$ : hemi-inattention, visual and sensory extinction, allesthesia, and anosognosia. These were recorded in categorical form as Present (1) or Absent (0).

Other neurological features identified by other studies as having prognostic significance for survival or recovery of independence were assessed. These were: level of consciousness, gaze paresis, visual field defect, power loss and proprioception. The level of consciousness was assessed using Oxbury et als 0-5 grading system. ${ }^{9}$ Gaze paresis, field defect, and proprioception were assessed as described and standardised elsewhere. ${ }^{17}$ The assessments were further simplified and recorded in categorical form as impaired (1) or normal (0) for level of consciousness $^{18}$ and proprioception ${ }^{18}$ and as present (1) or absent (0) for gaze paresis and field defect. ${ }^{18}$ Where patients were too drowsy (level of consciousness grade 3-5) or too aphasic to be assessed, this was noted.

Power loss was expressed by the Motricity Index, ${ }^{19}$ which converts the MRC grades of power into a figure that represents the percentage of "total motor recovery". This was entered as continuous data.

\section{Statistical analyses}

The relationship between the outcome groups (dependent variables) at three and six months and the clinical assessments at two to three days (independent variables) was examined by means of ANOVA for continuous data and by Chi Square tests for categorical data, using a significance level of $p<0.01$, in view of the number of analyses undertaken. Linear logistic regression was then carried out using the Logist proceedure of SAS. ${ }^{20}$ A "p value for inclusion" of 0.05 was set and the best stepwise solution sought. 


\section{Results}

Of the three month survivors 50 were independent, 19 mildly dependent, 10 moderately dependent and 10 severely dependent (table 3). At six months 54 were independent, 16 mildly, seven moderately and seven severely dependent. The severe and moderate groups were amalgamated as their numbers were too low for successful linear logistic regression.

ANOVA and Chi-squared tests showed that at both time points Level of consciousness, Gaze paresis, Visual Field Defect, Hemi-inattention, Visual Neglect Recovery Index and the Motricity Index were the significant predictor variables in survivors. Linear logistic regression found that at both time points, 3 variables made an independent contribution to outcome in survivors: Visual Neglect Recovery Index, Motricity Index and age (table 4).

When each patient was assigned to the outcome group with the highest probability, the predictive accuracy of the statistical model at 3 months was $78 \%$. Ninety per cent of independent and $80 \%$ of moderate/severe outcomes were correctly predicted. At six months the model had an overall predictive accuracy of $75 \%$, with $91 \%$ of independent and $71 \%$ of moderate/severe outcomes being correctly predicted (table 5). Prediction of mild dependence was considerably less accurate, many being predicted to be independent.

Table 3 Numbers of survivors in each outcome category

\begin{tabular}{lllll}
\hline & Independent & $\begin{array}{l}\text { Mildly } \\
\text { dependent }\end{array}$ & $\begin{array}{l}\text { Moderately } \\
\text { dependent }\end{array}$ & $\begin{array}{l}\text { Severely } \\
\text { dependent }\end{array}$ \\
\hline Number at 3 months & 50 & 19 & 10 & 10 \\
Number at 6 months & 54 & 16 & 7 & 7 \\
\hline
\end{tabular}

Table 4 Regression coefficients for significant predictor variables

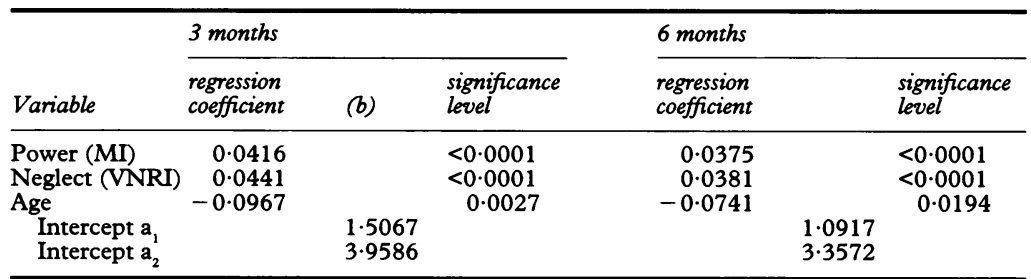

The probability, $p(1)$, of a patient being independent at 3 or 6 months is given by the equation $-\left(\mathrm{a}+\left\{\mathrm{b}_{1} \times \mathbf{M I}\right\}+\left\{\mathrm{b}_{2} \times \mathrm{VNRI}\right\}+\left\{\mathrm{b}_{3} \times\right.\right.$ age $\} \mathrm{p}(1)=1 / 1+\mathrm{e}$

$-\left(a_{1}+\left\{b_{1} \times M I\right\}+\left\{b_{2} \times V N R I\right\}+\left\{b_{3} \times\right.\right.$ age $\} p(1)=1 / 1+\mathrm{e}$
The probability, $\mathrm{p}(2)$, of a patient being mildly dependent is given by the same equation with a The probability, $\mathrm{p}(2)$,

The probability of moderate/severe dependence is given by $1-p(1)-p(2)$

Table 5 Comparison of predicted and actual outcome at 3 and at 6 months in patients presenting with neglect.

\begin{tabular}{|c|c|c|c|c|c|c|}
\hline & \multicolumn{6}{|c|}{ Predicted outcome } \\
\hline & \multicolumn{3}{|c|}{ at 3 months } & \multicolumn{3}{|c|}{ at 6 months } \\
\hline & $\begin{array}{l}\text { Barthel } \\
20\end{array}$ & $\begin{array}{l}\text { Barthel } \\
15-19\end{array}$ & $\begin{array}{l}\text { Barthel } \\
0-14\end{array}$ & $\begin{array}{l}\text { Barthel } \\
20\end{array}$ & $\begin{array}{l}\text { Barthel } \\
15-19\end{array}$ & $\begin{array}{l}\text { Barthel } \\
0-14\end{array}$ \\
\hline $\begin{array}{l}\text { Actual } \\
\text { outcome } \\
\text { Barthel } \\
20 \\
\text { Barthel } \\
15-19 \\
\text { Barthel } \\
0-14\end{array}$ & $\begin{array}{l}45 \\
(90 \%) \\
9 \\
(47 \%) \\
0 \\
(0 \%)\end{array}$ & $\begin{array}{l}5 \\
(10 \%) \\
8 \\
(42 \%) \\
4 \\
(20 \%)\end{array}$ & $\begin{array}{l}0 \\
(0 \%) \\
2 \\
(11 \%) \\
16 \\
(80 \%)\end{array}$ & $\begin{array}{l}49 \\
(91 \%) \\
9 \\
(56 \%) \\
0 \\
(0 \%)\end{array}$ & $\begin{array}{l}5 \\
(9 \%) \\
4 \\
(25 \%) \\
4 \\
(29 \%)\end{array}$ & $\begin{array}{l}0 \\
(0 \%) \\
3 \\
(19 \%) \\
10 \\
(71 \%)\end{array}$ \\
\hline
\end{tabular}

\section{Discussion}

Any statistical model which predicts the outcome of stroke should be based on a representative sample of patients, yield a result that makes clinical sense, and be accurate. Preferably, the resultant equation should be simple and the methods used related to standard clinical practice.

The model resulting from our study shows that in a series of patients surviving at least 3 months, the degree of independence is predicted by 3 factors: the severity of weakness at two to three days, the severity of neglect and the patient's age.

This model is based on a representative sample of stroke patients presenting to a district general hospital. The significant predictive factors make clinical sense. Power loss ${ }^{310}$ 182122 has previously been identified as a prognostic factor as have both the presence $e^{4}$ and the severity ${ }^{3}$ of visual neglect. Motor skills are important in self care, and the difficulties of using a hemiparetic limb in that side of space, or of compensating by using the non-weakened limb in that side of space, would be exacerbated by visual neglect.

Although ANOVA did not show that age was significant on its own, it was significant when taken into account with the other variables in logistic regression. The adverse effect of age has been noted in other studies. ${ }^{101821-3}$ This may reflect loss of neurological reserve after injury to the brain but may also reflect the lower expectations from physicians and therapists for older patients and thus less sustained attempts at active rehabilitation. The level of consciousness was not found to be an independent predictor of outcome. This contrasts with Allen's ${ }^{18}$ and Oxbury et al $\mathrm{s}^{9}$ studies, for example, which found that any impairment of consciousness, however mild, had a significant effect on outcome. The reason our study did not show this may well be that most patients with impaired consciousness died and were therefore excluded from the study, whereas Allen ${ }^{18}$ and Oxbury et al ${ }^{9}$ included death as an outcome.

The predictive accuracy of the model was high for independence (sensitivity $84 \%$, specificity $90 \%$ at three months) and for moderate/severe dependence (sensitivity $89 \%$, specificity $80 \%$ ). Prediction of mild dependence was less accurate. The accuracy of prediction in this and other ${ }^{3182-4}$ prognostic studies of stroke may be limited by several factors. Firstly, neither remedial therapy nor medical treatment is likely to have been standardised in the sample of patients examined; although nearly all patients received occupational as well as physiotherapy, none received specialised therapy ${ }^{56}$ for visual neglect and many of those who reached a Barthel score of 20 received less therapy than those with worse outcomes. Secondly, the pre-stroke level of independence may not have been clearly established. This may explain why, for example, a significant proportion of patients predicted to be independent had a Barthel score of $18-19$, due to pre-existing inability to bath or to climb stairs. Thirdly, factors 
such as motivation, known to affect outcome ${ }^{23}$ may not be measured.

The predictive equations derived from the model are relatively simple, requiring assessment of only two clinical variables, visual neglect and power. The assessment of power is closely related to the standard clinical method, and the VNRI is based on the Behavioural Inattention Test, ${ }^{11}$ which is being increasingly used by occupational therapists. The necessary mathematics can be performed by a basic pocket calculator. The equation is a little simpler than those produced by Fullerton $e t a l,{ }^{3}$ which contain six variables, some of which have to be weighted (Hodkinson's Mental Test Score) and some of which (for example, leg power, arm function) are not standardised measures.

Our study confirmed the findings of Fullerton $e t a l^{\beta}$ that the initial severity of visual neglect was a predictor of outcome, and that being "unassessable" for neglect was a good predictor of death. However, our study avoided the possibility of exaggerating the association of neglect with a poor outcome, by not allocating the mean VNRI score to the "unassessables" and by not including death as an outcome. The separation of "dependent" patients into two groups that reflected the practical difficulties of arranging a discharge, enabled us to identify a group in particular need of attention.

Lincoln et $a l^{25}$ have recently pointed out the limitations of prognostic studies in predicting exact outcome for individual patients, but stressed their usefulness in targeting a group of patients in need of special intervention. We suggest that our regression equations could be used in such a manner to select patients for randomised controlled trails of treatment of visual neglect.

SPS was supported by a grant from the Chest Heart and Stroke Association.

1 Leicester J, Sidman M, Stoddard LT, Mohr JP. Some determinants of visual neglect. $\mathcal{F}$ Neurol Neurosurg Psychiatry 1969;32:580-7.
2 Heilman KM, Watson RT, Valenstein E. Neglect and related disorders. In Heilman $\mathrm{KM}$, Valenstein $\mathrm{E}$, eds. Clinical Neuropsychology. OUP., 1985;243-50.

3 Fullerton KJ, Mackenzie G, Stout RW. Prognostic indices in stroke. $Q \mathcal{F}$ Med 1988;66:147-162.

4 Kinsella G, Ford B. Acute recovery patterns in stroke patients. Neuropsychological factors. Med $f$ Australia 1980;2:663-6

5 Weinberg J, Diller L, Gordon WA, Gerstmann LJ, Liebermann A, Lakin $\mathrm{P}$, et al. Visual scanning training effect on reading related tasks in acquired right brain damage. Arch Phys Med Rehabil 1977;58:479-86.

6 Robertson IH, Gray JM, Pentland B, Waite LJ. A randomized controlled trial of microcomputer-based rehabilitation for unilateral left visual neglect. Arch Phys Med Rehabil 1990;71:663-8

7 Ogden JA. Anterior-posterior interhemispheric differences in the loci of lesions producing visual hemi-neglect. Brain Cognit 1985;4:59-75.

8 Stone SP, Wilson B, Halligan P, et al. The assessment of visual neglect in acute stroke. I Neurol Neurosurg Psychiatry 1991;54:345-50.

9 Oxbury JM, Greenhall RCD, Grainger KMR. Predicting outcome of stroke: acute stage after cerebral infarction. BMJ 1975;3:125-7.

10 Wade DT, Hewer RL. Functional abilities after stroke: measurement, natural history and prognosis. $\mathcal{F}$ Neurol Neurosurg Psychiatry 1987;50:177-82.

11 Wilson B, Cockburn J, Halligan P. Development of a behavioural test of visuo-spatial neglect. Arch Phys Med Rehabil 1987;68:98-102.

12 Patten J. The cerebral hemispheres. Vascular diseases. Neurological differential diagnosis. London: Harold Starke, 1978.

13 Allen CMC. Clinical diagnosis of the acute stroke syndrome. $Q f M e d$ 1983;52:515-23.

14 Fisher CM Lacunar-strokes and infarcts: a review. Neurology 1982;32:871-6.

15 Wade DT, Hewer RL, Skilbeck CE, David RM, eds. Stroke. A critical approach to diagnosis, treatment and management London: Chapman and Hall, 1985

16 Stone SP, Patel P, Greenwood RJ, Halligan PW. Measuring visual neglect in acute stroke and predicting its recovery: the Visual Neglect Recovery Index. $\mathcal{f}$ Neurol Neurosurg Psychiatry 1992;55:431-6.

17 Stone SP, Halligan P, Wilson B, Marshall J, Greenwood RJ. Performance of age-matched controls on a battery of visuo-spatial neglect tests. $\mathcal{F}$ Neurol Neurosurg Psychiatry 1991;54:341-4.

18 Allen CMC. Predicting the outcome of acute stroke: a prognostic score. $\mathcal{\exists}$ Neurol Neurosurg Psychiatry 1984;47: prognos

19 Demeurisse E, Demol O, Robaye E. Motor evaluation in vascular hemiplegia. Eur Neurol 1980;19:382-9.

20 Harrell FE. The LOGIST procedure. SUGI supplemental library user's guide. Cary, NC. SAS Institute, 1983.

21 Marquardson J. The natural history of acute cerebrovascular disease: a retrospective study of 769 patients. Acta Neurol Scand 1969;45(suppl):38.

22 Wade DT, Skilbeck CE, Hewer RL. Predicting Barthel ADL score at 6 months after an acute stroke. Arch Phys Med Rehabil 1983;64:24-8

23 Henley S, Pettit S, Todd-Pokropek A, Tupper A. Who goes home? Predictive factors in stroke recovery. goes home? Predictive factors in stroke

24 Prescott RJ, Garraway WM, Akhtar AJ. Predicting functional outcome following acute stroke using a standard tional outcome following acute stroke usin
clinical examination. Stroke 1982;13:641-7.

25 Lincoln NB, Jackson JM, Edmans JA, et al. The accuracy of predictions about progress of patients on a stroke unit. $\mathcal{F}$ Neurol Neurosurg Psychiatry 1990;53:972-5. 